\title{
The Use of Digital Image Analysis and Rheological Tools to Characterize Nanofiber Based Textiles
}

\author{
Wannes Sambaer ${ }^{\mathrm{a}}$, Martin Zatloukal ${ }^{\mathrm{a}}$ and Dusan Kimmer ${ }^{\mathrm{b}}$ \\ ${ }^{a}$ Polymer Centre, Faculty of Technology, Tomas Bata University in Zlin, TGM 275, 76272 Zlin, \\ Czech Republic \\ ${ }^{b}$ SPUR a.s., T. Bati 299, 76422 Zlin, Czech Republic
}

\begin{abstract}
Polyurethane (PU) solved in dimethylformamide (DMF) was electrospun under one set of conditions on two different support textiles. The mechanical properties were measured and aerosol filtration tests were done. The hole size distribution was calculated with a new digital image analysis methodology on SEM images. It has been found that supporting textiles have very high effect on mechanical properties and filtration efficiency of nanofiber mats (even if their fiber diameter distributions were practically identical), which can be explained by different porosity of the prepared samples.
\end{abstract}

Keywords: Nanofiber, Electrospinning, Mechanical properties, Filtration, Digital image analysis. PACS: 81.07.-b, 61.46.Km, 62.23. $\mathrm{Hj}$, 62.25.Mn, 95.75.Mn

\section{INTRODUCTION}

In the last decade, there has been growing interest in nanofibers because the range of applications [1], like filter media, wound dressings [2, 3], sensor, catalysis, clothing, etc. is growing.

One possible method to produce nanofibers is electrospinning, where a high voltages is applied to produce fibers out of a polymer solution on a grounded collector [4] covered by a support textile. The knowledge about the processing parameters for electrospinning has a great importance for the properties of the nanofiber mats and is already investigated. An important kind of these parameters is material-related, like polymer type, viscosity, electrical conductivity [5], surface tension of the solvent, etc., and equipment-related, such as applied voltage [6], distance between collector and electrode, humidity [7,8], pressure [9] and temperature [9] in the chamber.

Several studies have already been done to measure the mechanical properties of single fibers [10-13] and nanofiber mats with different methods [7, 14], such as conventional tensile machines or more sophisticated equipment (e.g. atomic force microscope cantilever (AFM) or bending tests). Some investigators have recently turned to digital image analysis to characterize structures and predict some characteristics like porosity [15] and cell infiltration [16, 17].

Nevertheless, the influence of the supporting textile type (where the nanofibers are collected during electrospinning process) on the properties is still questionable and the 
use of digital image analysis can be useful to understand complex nanofiber mat structure and properties.

The main aim of this work is to investigate the effect of supporting textile on mechanical, filtration and structural properties of electrospun polyurethane based nanofiber mats by using different experimental and novel image analysis technique.

\section{EXPERIMENTAL}

\section{Material}

A polyurethane (PU) solution based on 4,4'methylenebisphenylisocyanate, poly(3-methyl-1,5-pentanediol)-alt-(adipic,isophtalic acid) and 1,4 butanediol (molar ratio 6:1:5) solved in dimethylformamide (DMF) was synthesized. The prepared solution suitable for electrospinning had a PU concentration of $11.5 \mathrm{wt} \%$, a viscosity of $0.99 \mathrm{~Pa} . \mathrm{s}$ and a conductivity of $151 \mu \mathrm{S} / \mathrm{cm}$ (adjusted by tetraethylamonium bromide).

Two different support textiles were used to collect the nanofibers. One textile was created by $35 \%$ poly(m-aramid), $63.8 \%$ poly(p-aramid) and $1.2 \%$ stainless steel, named as 'Sample 1', and the second support textile was non woven melt-blown polypropylene freshened with Polyfix N, named as 'Sample 2'.

\section{Electrospinning Process}

The obtained nanofiber textiles consisted out of three layers of nanofibers produced by electrospinning as described in [18] on the two different support textiles, which are described above. A voltage of $75 \mathrm{kV}$ was applied between the specially designed wire electrode and the grounded collector which was placed $180 \mathrm{~mm}$ from the electrode. The electrode rotated at the speed of $7 \mathrm{rpm}$, and the roll-up speed from the support textile was $0.16 \mathrm{~m} / \mathrm{min}$. The environmental conditions in the electrospinning-chamber were the temperature of $27.5^{\circ} \mathrm{C}$ and relative humidity $28 \%$.

\section{Filtration and Mechanical Test Methods}

The filtration test was done by measuring the amount of aerosol penetration by means of filter measuring system LORENZ adjusted for EN 143.

To test mechanical properties, Sentmanat Extensional Rheometer (SER) Universal Testing Platform was used on the rotational rheometer, Advanced Rheometric Expansion System (ARES) [19-21]. The tensile tests were carried out at a constant extensional strain rate of $0.01 \mathrm{~s}^{-1}$. The extensional stress was derived from the torque measured by a 2K FRTN1 transducer (provided by TA Instruments) and plotted as a function of extensional strain. 


\section{RESULTS AND DISCUSSION}

\section{Tensile Tests}

Figure 1 shows the results of the tensile tests with included error-bars. As it can be seen, there is a big differences between the mechanical properties of the nanofiber mats due to the different support textiles, which were used during electrospinning process. This graph shows that Sample 2 (where the melt blow support textile was used) has higher Young modulus and the rupture stress in comparison with Sample 1, which has been produced on aramid based supporting textile.

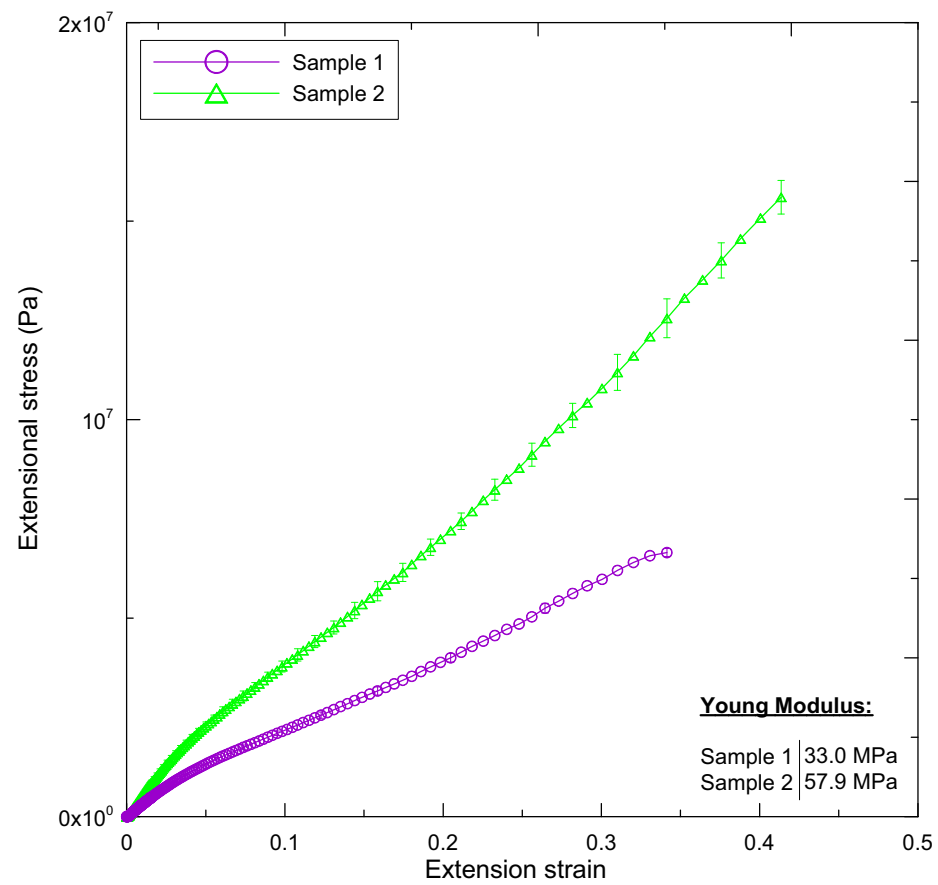

FIGURE 1. Measured extensional stress as a function of extension strain for Sample 1 and 2.

\section{Nanofiber Thickness Distribution}

The first approach to clarify the differences in mechanical properties and filtration efficiency is done by measuring the fiber-thickness distribution for both nanofiber textiles. The fiber-diameter distribution was determined for three detailed (zoom 5000x) SEM-pictures for each of the two textile samples on fixed places on the pictures by proper image analysis software. The scale on the SEM-pictures was used as standard reference for this type of measurement. For each picture approximately 500 diameters were obtained, which enables a reliable determination of the average 
and distribution of diameters. FIGURE 2 shows a principle sketch of the method used to measure these nanofiber thicknesses.

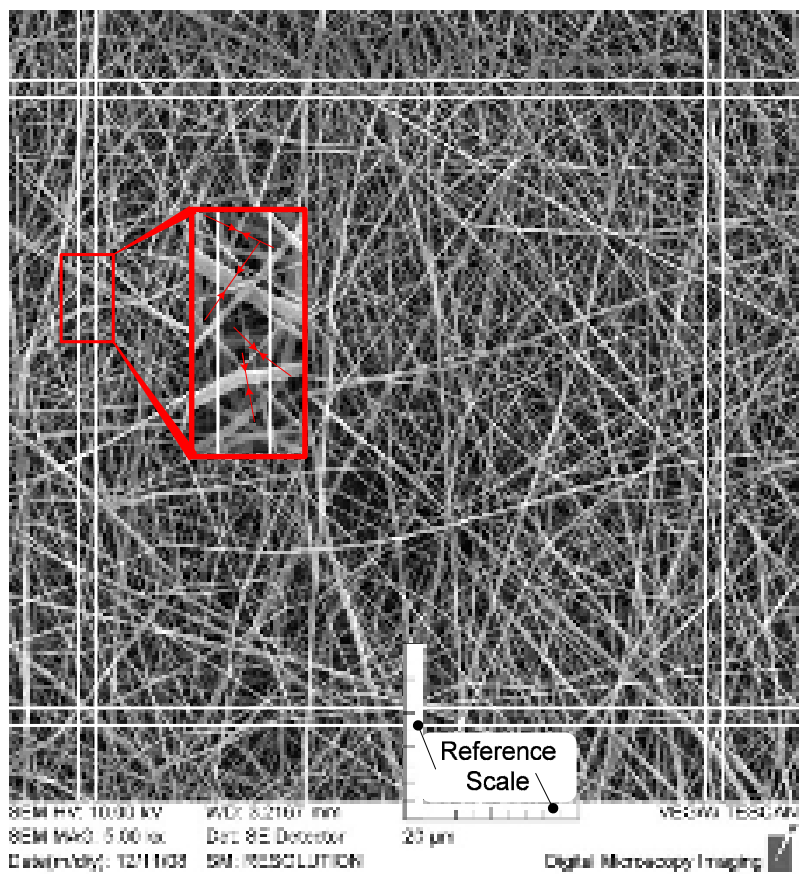

FIGURE 2. Visualization of the nanofiber thickness measurements on SEM picture.

Figure 3 shows the normalized Gaussian distribution curve which is based on the average and the standard deviation of the fiber diameter measurements for both samples. As it can be seen, there is only a small difference in the curves. It can be concluded that the fiber thickness distribution for both samples is virtually the same and thus the differences in the mechanical properties of both tested textiles cannot be explained through the fiber thickness distribution measurements. 


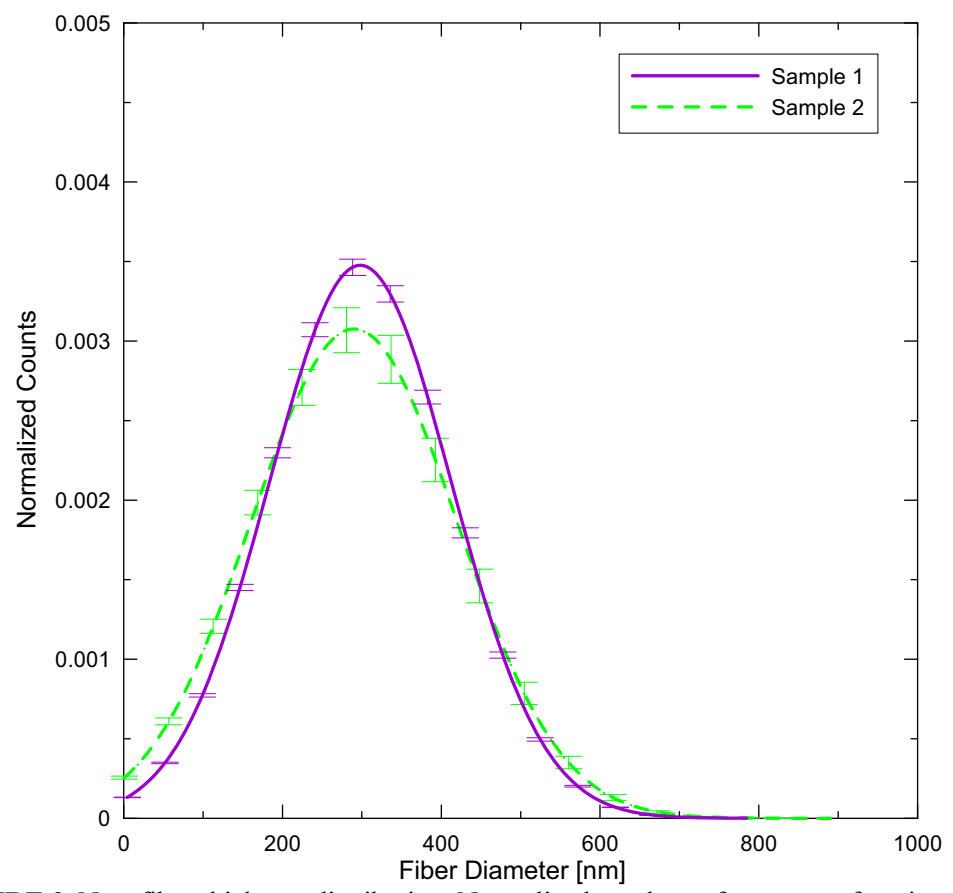

FIGURE 3. Nanofiber-thickness distribution: Normalized numbers of count as a function of the fiber diameter for both textiles.

\section{Structure Analysis}

The next step was to investigate the structure of the nanofiber textiles, which can have a relationship with the filtration efficiency and the mechanical properties. For this purpose, we have developed a novel image analysis method for Scanning Electron Microscope (SEM) pictures of nanofiber products based on very recent work of Ghasemi-Mobarakeh and Semnani et al. [16, 17]. The main idea of their recent work is to analyze the pores rather than each individual fiber by using different cells with three different characteristic sizes $(10,20$ and $30 \mu \mathrm{m})$ that could infiltrate the fiber based product. We have generalized this approach considering virtually unlimited number of cells (depends on particular computer memory allocation capability of the used PC) having sizes from units of nanometers to hundreds of $\mu \mathrm{m}$ which can pass through the fiber mat and also taking the 3D macroscopic shape of the nanofiber based textile properly into account. The numbers of circles are counted and normalized. In Figure 4, a part of the graphical results are shown to demonstrate how the proposed methodology works. 


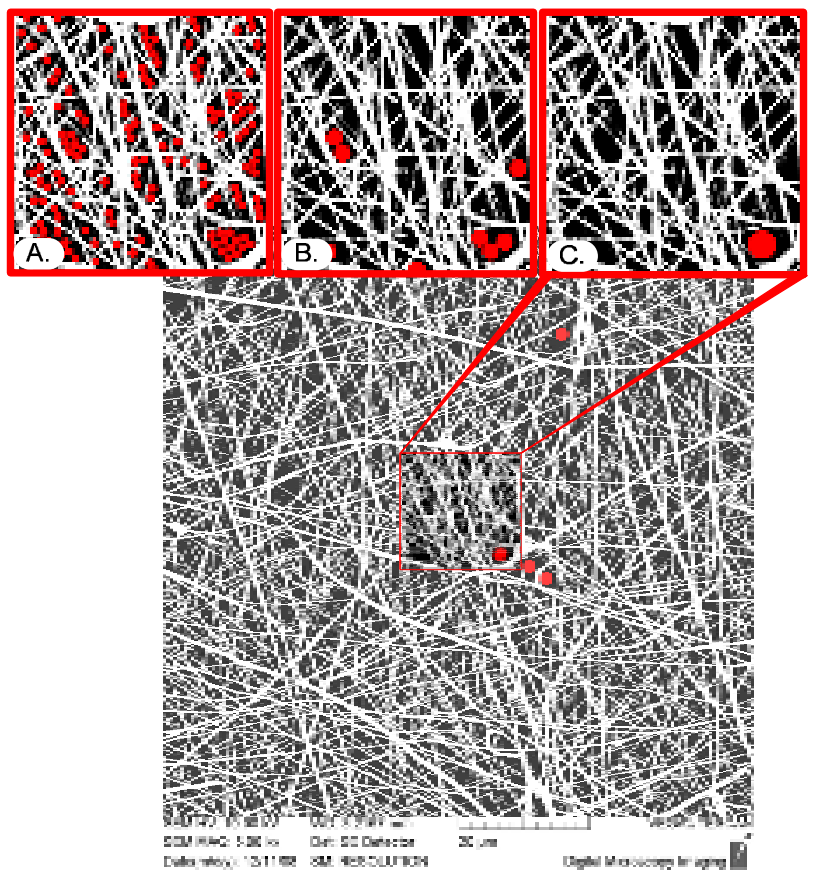

FIGURE 4. Partly results of the SEM nanofiber textile structure analysis: Circle diameters: $D_{A}=65 \mathrm{~nm}, D_{B}=125 \mathrm{~nm}$ and $D_{C}=205 \mathrm{~nm}$.

The raw data in the form of normalized numbers as a function of the circle diameter, plotted in Figure 5, shows a large difference between the number of holes for a certain hole size between two investigated samples. It can be seen that the amount of larger diameter of circles is much smaller in the case of Sample 2, which suggests that this sample will have better filtration efficiency than Sample 1. 


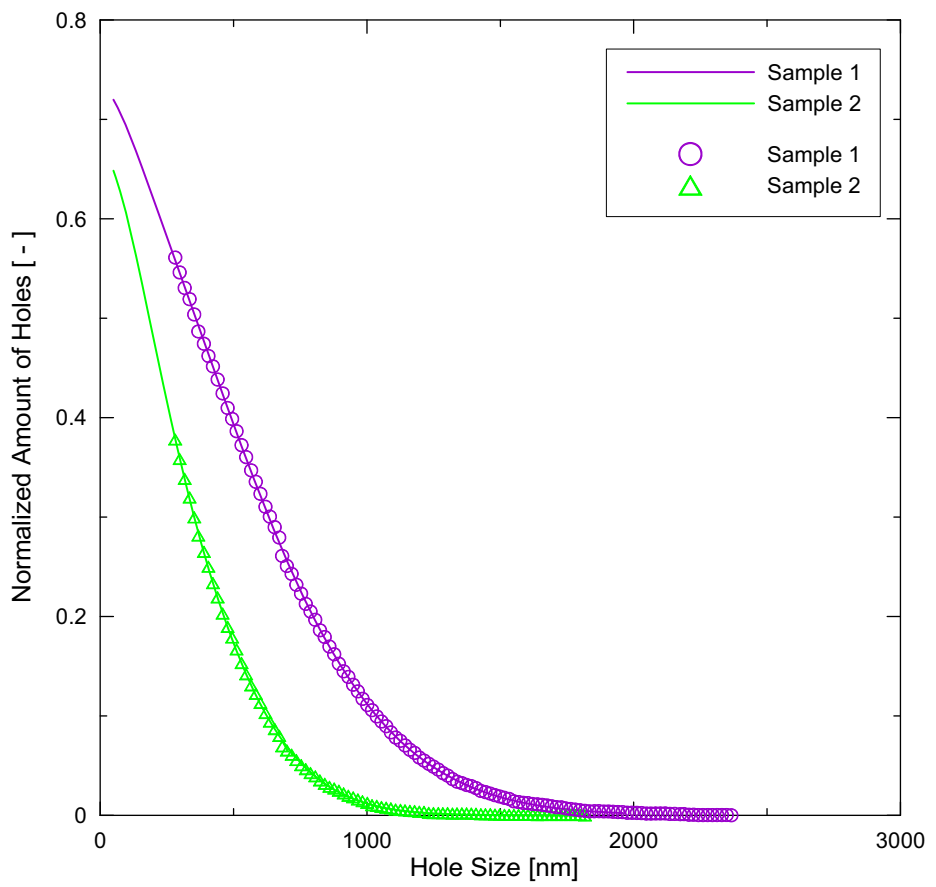

FIGURE 5. Raw and fitted data for the normalized amount of holes as a function of the hole size for both samples.

From this graph, Figure 5, the normalized derivative was calculated and plotted as a function of the circle diameter, which is shown in Figure 6. This yield a bell shape which provides detailed information about the pore distribution in the analyzed sample.

As it can be seen, the amount of bigger holes is larger in Sample 1, which can explain its less homogenous structure and worse mechanical properties in contrary to Sample 2. 


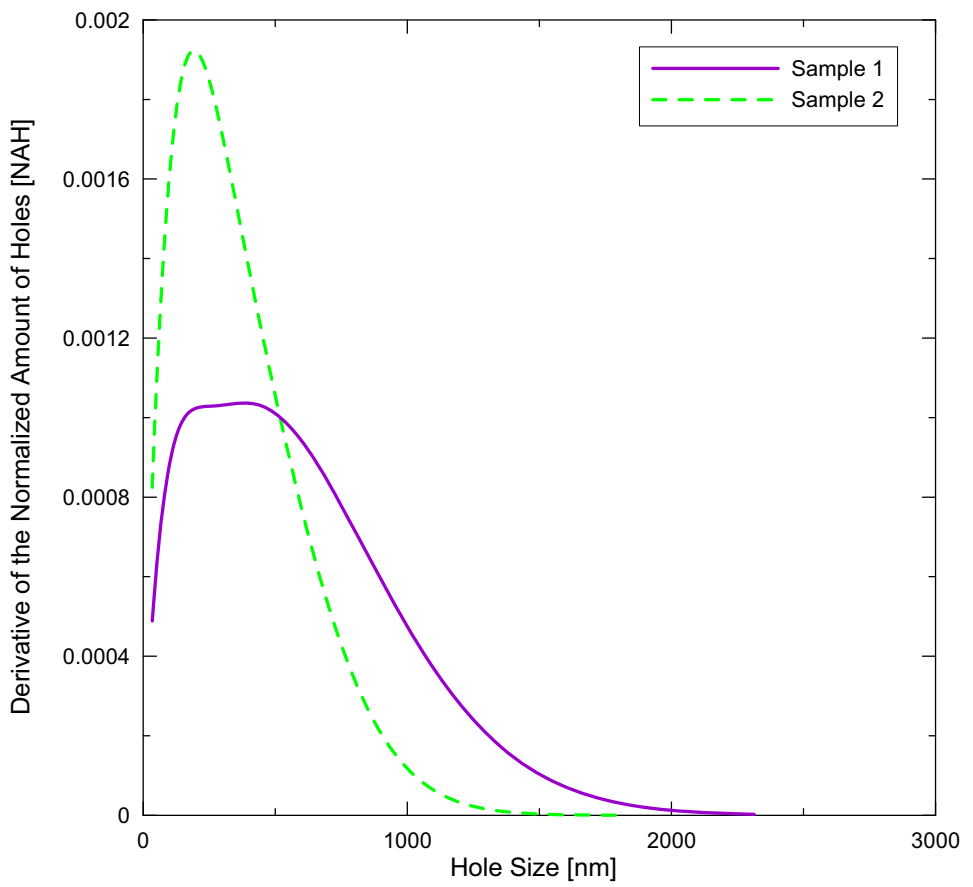

FIGURE 6. Normalized derivative of the amount of holes as a function of the hole size for both samples.

By using pore size distribution and calculated area occupied by nanofibers, filter efficiency curves for both samples have been theoretically calculated (see Figure 7). As can be seen in this figure, the filter efficiency of Sample 2 is much better in comparison with Sample 1. These predictions are in quantitatively agreement with the practical measured filtration data which was obtained from the aerosol tests. Sample 1 has an average aerosol penetration of $0.7852 \%$ and Sample 2 of $0.0393 \%$ 


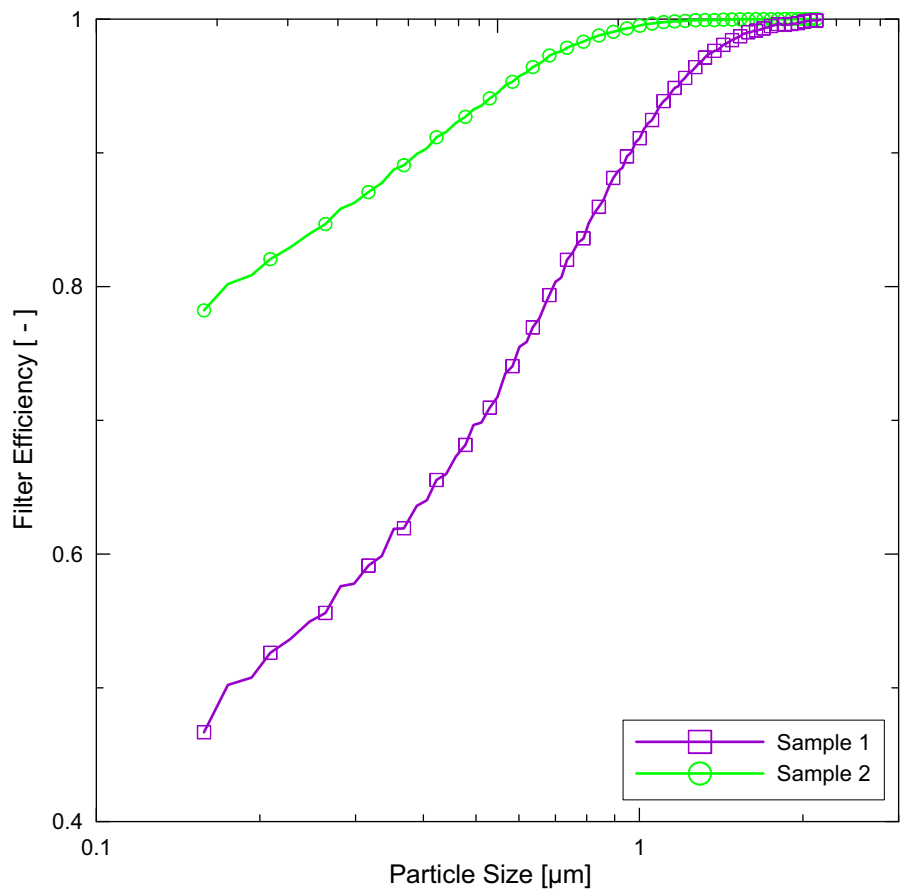

FIGURE 7. Simulation results for filter efficiency as a function particle size for both samples.

\begin{abstract}
Airfactor
Figure 8 shows the measured and theoretically determined airfactor (by using the proposed image analysis technique) as a function of maximum stress and E-modulus. The theoretical airfactor is based on the black white ratio of SEM images with were converted to binary pictures with a proper threshold level. As it can be seen, the airfactor of Sample 1 is higher than the air in Sample 2. It can also be seen that the error of the measured amount of air is much higher than the theoretical one because the practical method to measure the airfactor is difficult, due to small thicknesses of the spun textiles. The differences in airfactor for both samples can explain the big differences in mechanical properties of the nanofiber mats with the same polymer solution and processing conditions spun on different support textiles because the amount of PUR material is different.
\end{abstract}




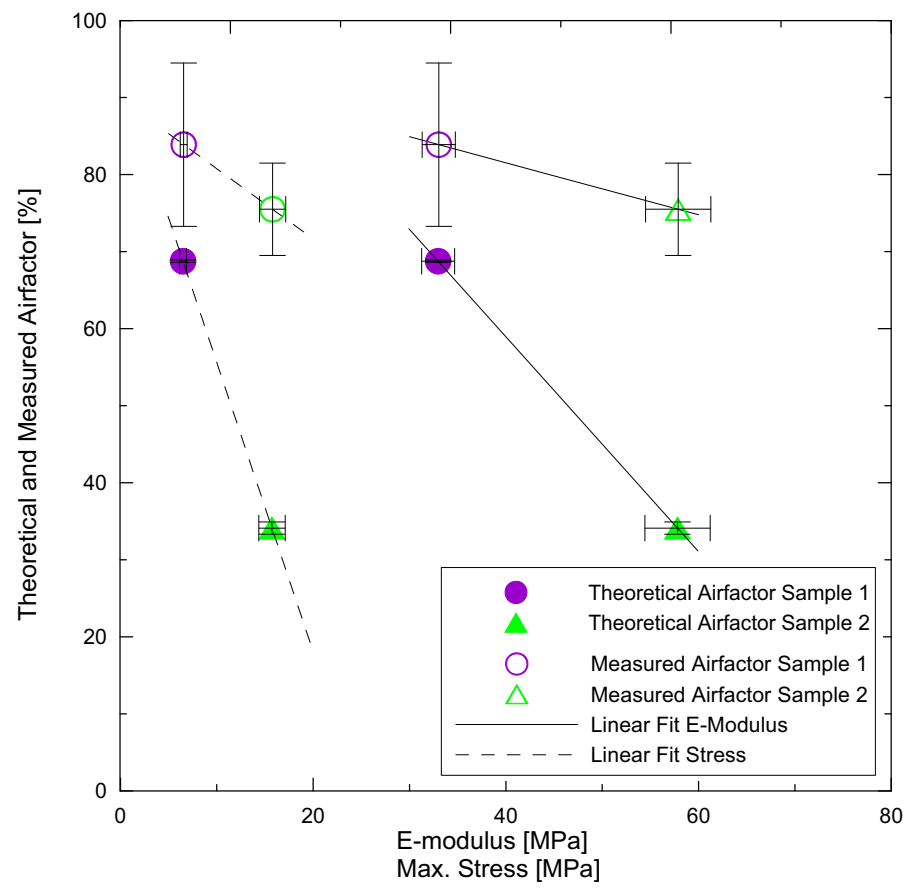

FIGURE 8. Measured and Theoretical Airfactor as a function of E-modulus and maximal stress for both samples.

\section{CONCLUSIONS}

Based on the performed experimental work and proposed novel SEM image analysis technique, it has been found that supporting textiles have very high effect on mechanical properties and filtration efficiency of nanofiber mats prepared by electrospinning process (even if their fiber diameter distributions were practically identical), which can be explained by different porosity of the prepared samples.

\section{ACKNOWLEDGMENTS}

The authors wish to acknowledge the Ministry of Education CR for the financial support of grant no. MSM 7088352101. 


\section{REFERENCES}

1. Z. M. Huang, Y. Z. Zhang, M. Kotiki and S. Ramakrishna, Composites Science and Technology 63, 2223-2253 (2003).

2. M. S. Khil, Cha Di, H. Y. Kim, I. S. Kim, N. Bhattarai, J. Biomed. Mater. 67B, 675-679 (2003).

3. S. H. Kim, Y. S. Nam, T. S. Lee and W. H. Park, Silk, Polym. J. 35, 185-90 (2003).

4. D. Li and Y. Xia, Adv. Mater. 16, 1151-1170 (2004).

5. T. Uyar, Flemming Besenbacher, Polymer 49, 5336-5343 (2008).

6. D. Fallahi, M. Rafizadeh, N. Mohammadi and B. Vahidi, Polym. Int. 57, 1363-1368 (2008).

7. E. P. S. Tan and C. T. Lim, Composites Science and Technology 66, 1102-1111 (2006).

8. S. Megelski, J. S. Stephens, D. B. Chase and J. F. Rabolt, Macromolecules 35, 8456 (2002).

9. S. de Vrieze, T. van Camp, A. Nelvig, B. Hagstrom, P. Westbroek and K. de Clerck, J. Mater. Sci. 44, 1357-1362 (2009).

10. X. Wang, Y. Yan, M. J. Yost, S. A. Fann, S. Dong and X. Li, Journal of Biomedical Materials Research Part A, 130-135 (2006).

11. Lu-Qi Liu, D. Tasis, M. Prato and H. D. Wagner, Adv. Mater. 19, 1228-1233 (2007).

12. E. P. S. Tan, S. Y. NG and C. T. Lim, Biomaterials 26, 1453-1456 (2005).

13. C. L. Casper, J. S. Stehens, N. G. Tassi, D. B. Chase and J. F. Rabolt, Macromolecules 37, 573-578 (2004).

14. X.F. Wang, X.M. Chen, K.H. Yoon, D.F. Fang, B.S. Hsiao and B. Chu, Environmental Science \& Technology 39, 7684-7691 (2005).

15. M. Ziabari, V. Mottahitalab and A. K. Haghi, Korean J. Chem. Eng.25, 923-932 (2008).

16. L. Ghasemi-Mobarakeh, D. Semnani and M. Morshed, Journal of Applied Polymer Science 106, 2536-2542 (2007).

17. D. Semnani, L. Ghasemi-Mobarakeh, M. Morshed and Mohammad-Hossein Nasr-Esfahani, Journal of Applied Polymer Science 111, 317-322 (2009).

18. D. Kimmer, P. Slobodian, D. Petrás, M. Zatloukal, R. Olejník and P. Sáha, Journal of Applied Polymer Science 111, 2711-2714 (2009).

19. M. L. Sentmanat, B. N. Wang and G. H. McKinley, J. Rheol. 49, 585 (2005).

20. M. L. Sentmanat, Rheol. Acta 43, 657 (2004).

21. M. L. Sentmanat, US Patent No.6, 578, 413 (2003). 
Copyright of AIP Conference Proceedings is the property of American Institute of Physics and its content may not be copied or emailed to multiple sites or posted to a listserv without the copyright holder's express written permission. However, users may print, download, or email articles for individual use. 